body generally, but especially about the in the splint a week after the occurrence of middle parts. I may observe, that when the accident; and the further progress of my there was difficulty of producing constitu- case will be seen from the following extract tional effects, by the internal administration from a letter, dated January 16 th, to $\mathrm{Ml}^{\circ}$. of the salts of zinc or copper, the combining with them the hydrochlorate of morphia caused them promptly to enter the system.

I would further observe, that although several cases did well without nitric acid, yet that in general its administration should not be omitted.

I have, at present, several very suitable and interesting cases under treatment. If, in the course of it, I should notice any, particularly worthy of attention, I shall communicate them through the pages of this valuable Periodical.

\title{
SLING FRACTURE BED.
}

\section{To the Editor of The LANCET.}

SIR:-With the view of bringing under the notice of my professional brethren the merits of the "sling fracture bed," invented by Mr. Greenhow, of Newcastle-upon-Tyne, I beg to lay before you the followirg case; I should premise that I do so from a conviction of the utility of the instrument in those cases where all other apparatus will be found inconvenient and ineffective.

On the 7 th of December last $I$ was called upon to attend a boy, aged about thirteen, who was employed in one of the collieries of the Countess of Durham, and who had been run over by some heavy coal waggons in the pit. I found the tibia of the left leg much shattered, the extremity of the upper portion of the bone being exposed to the extent of three inches; the greater portion of the integuments from the linee to the ankle had been destroyed; the head of the tibialis anticus was torn from its attachment to the upper and outer part of the tibia; the tibial artery was ruptured, about four inches above the ankle-joiut. There had been very considerable hamorrhage; the pulse was low and feeble, and the surface of the body was cold. I hesitated for some time whether it was safe to attempt to spare the limb, and at length determined that it would be ad. visable to do so. The leg was enveloped in a poultice, and laid upon a pillow, and stimulants were administered to the patient. On the second day after the accident the small portion of integument which adhered to the back part of the leg sloughed away, so that at this time it was entirely denuded of tegumentary covering.

During the last year, in the treatment of several cases of formidable compound fracture, I have found the numerons inconveniences of using the various splints in common use, and determined to test the merits of that invented by Mr. Greenhow, in the ase I have described. The limb was placed

Greenhow:-

"I immediately, on the receipt of your letter, containing your instructions, applied the sling fracture bed to the leg of my patient. I found no difficulty whatever in its application, and, indeed, was most agreeably deceived by its great simplicity and applicability to the very formidable case I was about to use it in. The extremities of the broken bone were brought into exact adaptation by the use of the foot screw; the limb assumed its natural figure and length, and the dressings were applied with an ease that astonished me. I have never since relaxed in the favourable opinion I at first formed of your invention. The lacerated leg of my patient has granulated and cicatrised in that gradual and healthy manner so much to be desired, and consolidation of the bone has progressed in a manner such as I never before witnessed in like cases. Previous experience, and comparative failure, may anthorise me in stating, with confidence, that your splint surpasses any apparatus we know of for the treatment of compound fracture of the leg. During the last eighteen months, and previously, several very formidable cases of compound fracture have fallen under my treatment, and the best and most careful methods I could adopt were attended with the most serious disadrantages, such as unhealthy and spongy granulations, of rapid formation, in the soft tissues; putrid smells; great pain in removing the splints during dressing, and afterwards, by their pressure upon sensitive and exposed wounds; slow union in the bones, in conseguence of the frequent remoral of splints; harassing inconvenience, and loss of time to the surgeon; and, lastly, more or less shortening, and deformity of the injured limb. In the single case in which I have used your splint, the granulations have gradually formed, and have been from the first firm, and healthy in appearance; the suppurative process has been less than in any other case $I$ have before seen; there has been about the extensive granulating surface no accumulation of putrid matter ; and, consequently, there has never been any unpleasant odour. The patient has never complained of pain, except the slight pain (of only momentary duration) in tightening the transverse bandages, by the sudden pressure of these arainst the raw surface behind the leg; the bed is never soiled; the patient can, with the utmost facility, raise his body, and no displacement or movement occurs in the fracture in consequence. The dressing: is so easy of accomplishment, that after one instruction the nurse may always do it; and the patient may be left in her hands for many days without prejudice. I may say, 
indeed, that $I$ am personally obliged to you for the great amount of labour you have been the cause of saving me in the case in ques- tion, and for the credit and fair reputation $I$ am sure your invention will earn for me hereafter. Matters are now so far advanced, that I can, without doubt, angur the most satisfactory cure, and one which before, I am ashamed to confess, it was never my good fortune to have effected in similar cases. I saw my patient to-day, and found the granulations so far advanced, that, with the view of checking exuherant action, I dressed the leg, simply, with a wet circular bandage, which I found so easy of application without moving the limb, that I ordered it to be renewed twice a.day. I will, in conclusion, add, that if I myself were unfortunately to break my lpg, whether the fracture were simple or componad, I would allow no other fracture apparatus to be applied than that, which you have had the great merit of inventing."

I am, Sir, your most obedient humble servant,

William Morrison,

Lecturer on Anatomy and Physiology, Newcastle Medical School.

Pelan, Chester-le-Street, Durham, Jan. 19, 1841.

\section{BURNT RHUBARB IN DIARRHCEA.}

\section{To the Editor of THE LANCET.}

Sin:-It may be useful to the profession to know the value of burnt rhubarb in diarrhcea. I have used it for seven years, and found it more serviceable in the diarrhoea, attendant on the last stage of consumption, than the chalk-mixture and opium, or any other of the usual remedies.

I have known it used, with the same pleasing effects, for more than twenty years, in incidental diarrhoas. After one or two doses, the pains quickly subside, and the bowels return to their natural state. The dose is from five to ten grains.

The manner of preparing it is to burn the rhubarb powder in an iron crucible, stirring it until it is blackened; then smother in a covered jar.

It loses two-thirds of its weight by the incineration. It is nearly tasteless. In no one case where I have known it given, has it failed. I have given it in port wine, milk, and water. Your obedient servant,

Middlesex Hospital. F. P. Hobly .

\section{TREATMENT OF PRURITUS ANI.}

To the Editor of THE LANCET.

SIR:- "A Subscriber" relates, in ThE Lancer of the $23 \mathrm{~d}$ ult, an intractable case $o$ pruritus ani, and wishes to be informed " how to cure the above most troublesome affec. tion." Having been an occasional sufferer for some years, I have much pleasure in stating what means have afforded me the greatest relief.

I believe that the affection is not essen. tinlly a local disease, but arises from a state of system in which small hard portions of feculent matter lodge in the folds of the mucous membrane of the lower bowels, producing a morbid sensibility of the extremities of the nerves about the anus, in the same manner that the irritation of a stone in the bladder is referred to the glans penis; although, by a long continuance of the com. plaint, and by the constant manifestations which the unfortunate patient is constrained to practise, keeping up the irritation, the morbid sensibility of the nerves of the part is rendered permanent, and the disease then assumes a local character.

During a recent attack $I$ took, at bedtime, two grains of mercury with chalk, with three of Dover's powder, and on the following morning-

$$
\begin{aligned}
& \text { Castor oil, } 3 \mathrm{iij} \text {; } \\
& \text { Liquor potassa, } 3 \text { ss ; } \\
& \text { Cinnamon water, } 3 \text { j. }
\end{aligned}
$$

This plan was persevered in for a fortnight, when the gums became rather tender, and all irritution subsided, while the bowels acted naturally, and the secretions were perfect. Since that period I have been but little troubled with the complaint. The occasional injection of warm water into the rectum, and sponging with the same at bed-time, are certainly very useful, and should not be neglected. I have also used, with advantage, five grains of the soap and opium pill as a suppository at night, fol. lowed by a mild purgative in the morning. Violent exercise is hurtful. I have found ripe fruit and vegetables very beneficial.

Hoping that the above remarks may be deemed of sufficient interest to obtain a place in your valuable Publication, I am, Sir, your obedient servant,

\section{A General Practitioner.}

London, Feb. 10, 1841.

P.S.-K reosote ointment, in the proportion of one drachm to an ounce of simple cerate, and the solid nitrate of silver, applied to the verge of the rectum, have, in some cases, been successful. I have tried the former in my own case, but without any benefit.

Another correspondent, Mr. Williamson, advises the use of cold water sponged over the part several times in the day; and the zinc ointment, diluted with one-half of simple cerate, to be applied after each ablution. To the local treatment may be added, with advantage, the exhibition of the following pills, one of which is to be taken occasionally :- 